\title{
Unmanageable Multiplicity: Consumer Transformation Towards Moral Self Coherence
}

\author{
Michal J Carrington \\ University of Melbourne \\ Benjamin A Neville \\ University of Melbourne \\ Robin Canniford \\ University of Melbourne
}

\section{Structured Abstract:}

Purpose

The study explores: (1) consumer experiences of intense moral dilemma arising from identity multiplicity conflict, expressed in the marketplace, which demand stark moral choices; (2) consumer response to intensely felt moral tension where their sense of coherent moral self is at stake.

\section{Design}

We gathered ethnographic data from amongst ethical consumers, and theorised the data through theory of life projects and life themes to explain how multiplicity can become an unmanageable problem in the midst of moral dilemma.

\section{Findings and Research Implications}

We reveal that in contrast to current notions of liberating or manageable multiplicity conflict, some consumers experience intense moral anxiety that is unmanageable. This work also contributes to knowledge of multiplicity, consumer life themes and life projects, moral dilemma, and ethical consumption by showing that experiences of intense moral tension can provoke consumers to iteratively transform self and consumption choices to construct a coherent moral self. We identify this transformation as the meta life project.

\section{Practical and Social Implications}

This study provides guidance to companies, marketers, public organisations, and activist groups seeking to understand and harness consumers' moral codes to promote ethical consumption practices.

\section{Originality}

We extend current theory of multiplicity into the moral domain to illustrate limitations of framing consumer experiences of multiplicity conflict as being either liberating or manageable when consumers' sense of moral self is at stake. This article is of interest to academic, marketing practitioner, and public policy audiences.

\section{Keywords:}

Moral dilemma, multiplicity, fragmentation, conflict, identity, ethical consumer, ethical consumption gap, life theme, life project, ethnography, morality. 


\title{
Unmanageable Multiplicity: Consumer Transformation Towards
}

\author{
Moral Self Coherence
}

\begin{abstract}
"When I go somewhere [to shop] that isn't an option normally because the ethical product isn't there - it might be a birthday, it might be some event, or I'm in a hurry - I make a compromise. Those are the things that make me feel worse... I will feel really disappointed in myself. I think that what I have learned over time is that if I do continue to make the choices that matter to me, my anxiety is lower...Living ethically is like a total shot in the arm of happiness - as we have changed we have become happier". (Sarah, interview data)
\end{abstract}

Sarah expresses the tension faced when her consumption choices contradict her established moral frameworks. In this paper we investigate instances that place consumers' sense of moral self at stake through the lens of identity multiplicity. In contrast to perspectives that frame multiple identities as liberating or manageable through coping strategies (e.g. Firat, Dholakia, and Venkatesh, 1995; Goulding, Elliott, and Shankar, 2002), we show that in morally charged situations of multiplicity conflict, some consumers - such as Sarah - experience moral "anxiety" that is unmanageable. Such intense experiences trigger a process of realignment: a transformation of self and consumption choices to eliminate sources of moral conflict and progress towards a more coherent sense of moral self.

Our paper begins by explaining the complex, fragmented experiences of consumer multiplicity from which these moral tensions can emerge. Following this we offer a brief review of moral aspects of consumption and identity to illustrate that existing studies in our field have not fully explained the moral conflict arising from identity multiplicity. Specifically, our literature review reveals that the contexts from which existing research is derived obscure identity conflicts that demand moral choices and gloss over the resulting moral strains. To explore this phenomenon, we theorise data gathered from an ethnography of ethical consumption choices through the 
concepts of life projects and life themes (Mick and Buhl, 1992; Schau et al., 2009; McCracken, 1987), which enables us to explain how multiplicity becomes an unmanageable problem in the midst of moral consumption dilemmas, and what processes are enacted to overcome these situations.

In so doing, we make five specific contributions. First, we extend concepts of identity multiplicity and fragmentation by showing how identity conflict and life project conflict reflect clashing higher-order 'life themes'. Second, in contrast to the notion that multiplicity is liberating (Firat and Venkatesh, 1995) or managed through coping strategies (Bahl and Milne, 2010), we show that the tension arising from moral dilemmas in the marketplace can be unmanageable. Third, we show how these consumers' moral life themes drive a transformation towards a unified, coherent experience of moral self that we term a meta life project. Fourth, we provide an enriched understanding of the dynamics underlying the well documented 'ethical consumption gap'. Finally, we discuss the implications of our findings for consumer research, public policy and marketing practice.

\section{Multiple Identities in the Marketplace}

In late modernity, consumers are often understood as moving through heterogeneous life worlds, expressing a proliferation of styles and choices that result in multiple senses of identity (Heelas et al., 1996). Marketing research has conceptualised the 'self' as a multi-faceted collection of these identities, which are activated by and expressed through relationships, environments, and a variety of consumption resources (Schouten, 1991, Bardhi et al., 2012, Brewer, 2001). The very idea that identity is multiple infers that these consumption patterns are in some way different from one another (Ahuvia, 2005; Ustuner and Holt, 2007; Bahl and Milne, 2010), which in some cases leads 
to experiences of fragmentation, and incommensurable expressions of identity through consumption (Bahl and Milne, 2010; Ahuvia, 2005; Tian and Belk, 2005; Firat et al., 1995). Existing research places these fragmented experiences in two dominant frames that we label liberated multiplicity and managed multiplicity.

The liberated multiplicity frame is grounded in post-modern perspectives (Firat and Venkatesh, 1995) that suggest that consumers enjoy fragmentation and the contradictions arising between multiple identities, as these free them from a unified sense of self. Studies situated in experiential consumption contexts generally represent consumers as seeking liberation from fixed modes of life, self and community (e.g. Belk and Costa, 1998; Kozinets, 2002). In these cases, plurality and contradiction are celebrated as restorative and escapist pleasures. The incommensurability of two or more identities - every-day life and extraordinary consumption are mutually reinforcing, one identity offering restorative time out from the other (Goulding et al. 2009).

Nevertheless, another stream of research frames identity multiplicity as demanding more careful management. This managed multiplicity perspective is more in line with ideas of 'reflexive modernization', in which tensions that result from multiple identities (Bauman, 2013), cause distress (Bahl and Milne, 2010). In these cases, coping strategies are deployed to construct a manageable sense of self coherence (Ahuvia, 2005), to avoid identity multiplicity conflict (Bardhi, Eckhardt and Arnould, 2012) and to cope with the "existential insecurity posed by the fluid and perpetually contingent conditions of postmodern society" (Luedicke, Thompson and Giesler, 2010, p 1029).

Notwithstanding the contributions of these perspectives, however, we suggest that existing research has not fully explained the interplay between conflicting consumption identities. In both 
liberated multiplicity and managed multiplicity, consumers continue to live with identity contradictions expressed through contradictory consumption choices. This is unsurprising in cases of liberated multiplicity, because these experiences are designed to offer pleasurable separation from quotidian life. The case of managed multiplicity offers more clues as to the tensions that consumers experience, but many of these studies offer snapshots of multiplicity conflict captured in isolated moments and/or bounded by the research site. In other words, the extant research does not explain what happens to consumers after the event, as one situation flows into another (Bennett et al., 2013). In order to further investigate and theorise the experience of multiplicity in consumers' ongoing lives, we now probe one area of managed multiplicity in more detail, and find that in morally-charged domains of consumption, coping with multiplicity conflict can become very problematic for some consumers - in situations of unmanageable multiplicity.

\section{The Morality of Multiplicity}

The study of moral self expressed in consumer choice is a relatively new area in marketing research. In contrast to ethics - the contextual rules and frameworks used by consumers to connect with their moral values in particular consumption situations (Foucault, 1992) - we define morality as overarching codes and value systems that establish right from wrong for individuals and communities across situations and over time (Crane and Matten, 2010). Despite the limited number of studies that engage with moral self, morally charged choices appear to engender tensions and coping. For example, Luedicke et al. (2010) illustrate the coping strategies that result from brandbased morality conflicts between groups of consumers. Kozinets and Handelman (2004), Varman and Belk (2009), and McGraw, Schwartz and Tetlock (2012) illustrate consumers' experiences of tension arising from moral contestations with corporations. Further, Weinberger and Wallendorf 
(2012) illustrate the embodiment of morality in consumption when revealing the importance of the intersections between moral and market economies to social cohesion. More recently, Saatcioglu and Ozanne (2013) have explained how morality is a mechanism of social stratification for working class consumers.

While studies investigating consumers' sense of moral self are sparse, the expression of morality in consumption situations - ethical consumption - has been extensively researched. Initially grounded in 'green/environmental' issues, this body of knowledge has expanded considerably to consider complex webs of 'sustainable' (Kilbourne and Beckmann, 1998; McDonagh, 1998; Crane and Matten, 2004; McDonagh and Prothero, 2014) and 'ethical' (Shaw and Connolly, 2006) consumption. Sources of consumer motivation underpinning the growth in ethical consumerism include: the evolution of consumption as a means of constructing self-image and extended self (Niinimaki, 2010); a growing sense of responsibility and empowerment to address global issues (Connolly and Prothero, 2008); the politicisation of consumption in the face of unsustainable consumption consequences (Giddens, 1990); and, as a result of consumers being increasingly confronted with the externalities of our consumption-driven society (Newholm and Shaw, 2007; Chatzidakis and Lee, 2013).

Further explicating consumer motives, Barnett, Cafaro and Newholm (2005) delineate two distinct meanings of ethical consumption: (1) ethical consumption can relate to the 'ethics of consumption', which concerns the ethics of capitalist market systems and the reduction of overall consumption; and, (2) ethical consumption can be viewed as a medium for moral action. Though distinct, these sources of ethical consumption motivation and action are often combined, linked, and simultaneously displayed by ethical consumers (Barnett et al. 2005; Smith 2008). As Connolly 
and Prothero (2008) suggest, however, ethical motivations are just one aspect of consumer experience negotiated within ongoing, multi-faceted identity projects.

The multiplicity of sources of motivation, coupled with the broad range of issues considered by ethical consumers - such as fair trade, animal welfare, worker's rights, environmental issues - and the influence of other competing aspects of their self and life, results in complex and contested consumption choices (Shaw and Shui, 2002; Harper and Makatouni, 2002; Connelly and Prothero, 2008). Ethical consumption studies exploring sites of conflict and experiences of tension arising from this complexity have largely focused on the contradictions of ethical consumers - the ethical consumption 'gap' - and the coping strategies deployed by these consumers to manage the resulting moral anxiety (e.g. Carrington, Neville and Whitwell, 2014; Szmigin, Carrigan and McEachern, 2009; Chatzidakis, Hibbert and Smith, 2007; Nicholls and Lee, 2006). Similarly, anti-consumption and voluntary simplicity studies - as forms of ethical consumption - illustrate the conflict and existential stress experienced when consumption choices are inauthentic to ideal visions of self (e.g. Cherrier, Black and Lee, 2011; Cherrier, 2009; Zavestoski, 2002) or juxtapose normative codes clash (Guilliard and Roux, 2014).

In these studies of moral self (e.g. Luedicke et al., 2010) and ethical consumption (e.g. Chatzidakis et al., 2007), the presence of morality leads to the kinds of tensions generally associated with managed multiplicity. Despite introducing morality and ethics into the marketing and consumer research arenas, however, these studies have largely isolated investigation of moral self to: (1) singular and specific contexts, such as Hummer enthusiasts (Luedicke et al., 2010) or a trailer park (Saatcioglu and Ozanne, 2013); and (2) singular and specific manifestations of moral self in ethical consumption choices, for example fair trade goods (De Pelsmaker and Janssens, 2007) and organic production (Cherrier, 2007). The overarching notion of moral self as a source 
of ethical consumerism remains an undefined backdrop to this body of research. While not the purpose of these studies, our field has yet to consider the consumer experience of moral self and moral contests across multiple domains of everyday life. With this in mind, it is important to explore further the moral dilemmas experienced when differing priorities intersect in consumption choices, resulting in anxiety too problematic to manage through the deployment of coping strategies. Our study investigates the complexity of consumers' moral expressions and dilemmas within fragmented, multi-faceted, ongoing experiences of life. This wider perspective is important because it allows us to acknowledge the tensions experienced by some consumers when struggling with competing priorities and contradictory choices, and more importantly, what they do to solve these moral tensions over extended periods of time.

As such, we move beyond isolated and externalised perspectives of moral conflict to ask: how do consumers' experiences of fragmentation and multiplicity impact their sense of personal moral coherence, and what are the locations of moral conflict? Second, we acknowledge that while some consumers experience moral dilemmas that are too intense to manage, other consumers are able to deploy coping strategies, such as neutralization, to manage and cope with moral contradiction in their consumption choices, embodying the well documented 'ethical consumption gap' (Chatzidakis et al., 2007; Carrigan and Attalla, 2001; Carrington et al., 2014; Nicholls and Lee, 2006). Thus, we ask: under what conditions does a deep sense of moral discord constrain consumers' ability to contain the resulting tension through coping strategies? Finally, we find that the static approach and domain specificity of previous investigations of consumer identity multiplicity research limit our understanding of the contingencies of liberated fragmentation, coping strategies and related consumer struggles. Thus, we ask, what processes of transformation enable consumers to restore their sense of morally coherent self? To answer these questions, we 
now articulate theory through which we can view multiplicity and the resultant moral dilemmas that consumers experience in the marketplace.

\section{Consumer Transformation: life projects and life themes}

To understand how moral dilemmas arising amongst conflicting identities are experienced, and how these experiences evolve, we draw on the concepts of life projects and life themes (McCracken, 1987, Mick and Buhl, 1992, Schau et al., 2009). Life projects are ongoing consumption processes through which consumers construct and transform life and self (Schouten and McAlexander, 1995). A single life project encapsulates the evolution of a collection of concepts, such as a variety of identities, relationships, and lifestyle (McCracken, 1987, Arnould and Thompson, 2005), such as the life projects of 'career' and 'parent' (Thompson, 1996). A life project requires conscious choices and purposeful work, and is directed towards an end goal of an idealised self and lifestyle (Arnould and Thompson, 2005; Schau et al., 2009; Schouten, 1991).

Consumers, however, often work on a selection of multiple life projects simultaneously (Thompson, 1996). These are guided by life themes, "profound existential concerns that the individual addresses - consciously or not - in the course of daily events" (Mick and Buhl, 1992, p 318). In contrast to dynamic life projects, life themes tend to be more enduring frameworks that guide the selection of desired life projects, ideal identities and ultimately consumers' practices in the market (Mick and Buhl 1992; Schau et al. 2009). We draw upon life projects and life themes as a means to understand the evolving consumer experience of multiplicity conflict across time and space.

Ethical consumption is an ideal site to examine moral conflict and dilemmas as the contradictory consumption practices of ethically-minded consumers are well documented (Belk, 
Devinney and Eckhardt 2005). In these cases, the morality that extends from 'ethical consumption' is often contested across different kinds of consumption (Carrington, Neville, and Whitwell 2014).

\section{Research procedures}

To capture the conflicts, two sequential data sets were collected. The first was recruited through the email newsletter of an ethical consumerism group. Four informants were purposively sampled based on their self-perceptions as being on the 'extreme' end of the ethical consumption spectrum. Semi-structured interviews lasting between two and three hours took place in informants' homes or alternative locations where they felt that they could speak freely. Interviews began with grandtour questions such as, "what do ethical consumption and ethical consumerism mean to you?". As each interview progressed, the prompts became increasingly focused on shopping practices and consumption contradictions. During the following five months, these informants also participated in accompanied shopping trips, written and photographic shopping diaries, and projective interviews. The first author was also invited to attend a variety of social events such as ethical consumer film nights, informal dinners, and sewing workshops where informants transformed the fabric from second-hand clothing into new garments.

A second data set was recruited using snowballing techniques. Nine informants who described themselves as either 'moderate' or 'newly aware' ethical consumers were chosen to participate in similar procedures to the first data set. During this period, the first author participated in a variety of social events such as community cooperative workshops and a sustainability festival. The combined data set (see table 1) includes a range of demographics to ensure that varying life experiences and perspectives were integrated into the study (Cherrier, 2007), thus spanning a broad 
variety of ethical consumerism concerns. All informants resided in urban (inner-city or suburban) locations.

\section{INSERT TABLE 1 HERE}

The nine-month research process generated 445 pages of interview transcriptions, 34 photographic images, 63 minutes of video, and 49 pages of field notes. Initially, data were open-coded to capture emerging themes and concepts (Corbin and Strauss, 2008), leading to a total of 2605 coded observations. A grounded approach was taken to micro-analyse the open-coded data, and abstraction methods were employed to identify higher-order theoretical concepts and relationships (Spiggle, 1994). The analysis then moved into a constant comparative technique, to further develop the properties and dimensions of emergent concepts until theoretical saturation was reached (Corbin and Strauss, 2008). Several strategies were employed to ensure the trustworthiness of the data and analysis: triangulation across methods, sources and research sites; prolonged engagement and immersion; the combination of several written, audio and visual data recording methods; the use of negative case analysis; selected member checks; and, regular researcher debriefings (Arnould and Wallendorf, 1994; Hammersley and Atkinson, 2008; Wallendorf and Belk, 1989; Miles and Huberman, 1994; Lincoln and Guba, 1985; Marcus, 1995).

\section{Findings}

Our study findings are structured as follows: first, we establish that the 'ethical' consumption practices of our informants can be conceptualized as a life project. We discover, however, that informants simultaneously work on multiple life projects guided by multiple life themes that can 
clash, resulting in multiplicity conflict and experiences of moral tension and compromise. Second, the data and analysis reveal that multiplicity conflict, resulting from the interplay between informants' contesting life themes and life projects, often manifest in contradictory consumption choices. These contradictions resulted in an intense sense of moral self incoherence that became intolerable for those informants whom morality had become a dominant life theme. Third, our findings reveal that an intense desire for a coherent moral self works as a powerful motivation to embark upon a meta life project of alignment - an encompassing reconstruction of self - in an attempt to construct a re-unified sense of moral self.

\section{Moral Consumption as a Life Project.}

The moral consumption life projects of our informants were revealed in their everyday consumption practices. Work and progression on these life projects was driven by informants' desire to be "aware and intentional" (Adam) in their consumption choices, considering the impact and ethicality of their daily consumption practices. These visions of being a moral and aware consumer were centered on specific issues of ethical concern to the individual, such as animal welfare and cosmetic testing or consumption waste and environmental degradation.

Informants' moral consumption life projects were iterative. For example, Susan's summation of the expansion of her ethical consumption over the past 40 years illustrates the dynamic nature of moral consumption practices as a life project:

"I'm 67 years old, so I have to think back quite a long way...I was newlywed with the brand new house on a brand-new block and doing our lawn, didn't question the point of lawns, and weeds were endlessly growing in the lawn and I can clearly remember saying, ... there must be some chemical we can just squirt on these things! Now, this is 1964, it would have been not long after that that I became aware that having some chemical to squirt the lawn with is not a good thing... Then, early 
70's I became aware of a church-wide program called 'Action for world development'. It was a really good education program where all the people from different churches were encouraged to form groups and come to these gatherings and there was a real buzz in the air and people came along and we all became aware then of the fact that we were consuming way beyond our share of the world's resources. It was about equity and equitable share of resources worldwide, and we all thought OK we'll stop buying things, we'll think twice before buying anything. So, that was clearly a key thing for me and I had two little children - this is mid70 's, and I decided not to drive my car everywhere. And so, I started to cycle everywhere that I could, and that's when I started to compost everything so I didn't create waste with all the rubbish and food. So, I have adopted a particular lifestyle that means I can do the things I can do, and not lose too much sleep over all the things that are still completely inequitable about our lifestyle".

Susan's story reveals her expanding moral consumption practices and persistent life project work as she chips away at her consumption and reconstruction of self over forty years. Her narrative also illustrates how she sees a gradual expansion of her ethical consumption life project from a single issue - equitable sharing of resources - to many issues rolled into her now multidimensional moral consumption life project. Similarly, Sarah articulates the expansion of her moral consumption project from a single issue to a complex web of consumption practices: "initially it was social [ethical concerns], but now very broadly triple bottom line ${ }^{\mathrm{i}} .$. there are more and more things where our contribution just drops and drops".

As well as being a story about increasing awareness, integrating additional ethical concerns that become a "way of life", Susan's story is also about the evolution of self. As Susan gradually threads more and more ethical issues into her life, she also sheds many forms of her 'old' consumption identities and practices to move away from the "whole package of consumerism". This evolution is as much about moving away from what Carl calls "mindless consumerism" as it is about moving towards moral consumption. Similar to the informants in Schouten's (1991) study of cosmetic surgery recipients, morally-charged consumption life projects encompass 
simultaneous self deconstruction and reconstruction, where our informants moved away from past selves and toward reconstructed ideal selves (Markus and Nurius, 1986). Informants' visions of undesired self to be avoided often shared common aspects with their own past identities in the consumption sense, and it was these layers of undesired self that were being stripped away and replaced in the process of self reconstruction. For example, when reflecting on her consumption compromises, Sarah suggests: "It's a sense of I weakened and I capitulated to something low or a value that represents an old me who needed to be healed or needed to be strengthened".

Informants' moral consumption practices can be conceived as life projects that are a continuing and expanding process of self-renewal. Our data and analysis also revealed that moral consumption life projects were directed and guided by an overarching moral life theme.

\section{Moral Life Themes}

Life themes are enduring frameworks that individuals use to interpret and guide their life (Schau et al., 2009; Mick and Buhl, 1992). Our study uncovered an overarching moral life theme that was a powerful scaffold structuring the lives and daily consumption choices of all informants. For Alex, this encompassing moral life theme was about being a person of "integrity" in the interactions and practices of daily life.

The moral life themes of informants were much broader, connected and abstract than a few isolated ethical/moral concerns. Rather, their moral life themes were a guide to living a moral life. Living out their moral life theme was about being authentic to their beliefs, as Adele says, "my life needs to reflect what I value". Similar to the informants in Mick and Buhl's (1992) study, family role-models had been highly influential in the development of our informants' moral life themes. Sarah, for instance, spoke of having "a really strong social justice model growing up" in 
a family that "stood up for things" and the influence that this upbringing had on her moral development. Informants continued the cycle of moral life theme socialisation within their own families. For example, Peta first describes how as a "bush kid" growing up in Africa, her African minders impressed upon her in an "indirect way" a constant awareness of the environment and that everything you do has an impact. She then tells of how she and her husband have raised their children "with a view to being fair and just in whatever they do and in the interactions they have. We must have lived it as well because the three of them are in some ways much harder about the ethical issues than we are".

Informant's moral life themes form an overarching scaffold that guides the ongoing construction of life projects. Once formed, these moral life themes were long term and enduring frameworks: "the last let's say twenty, thirty years [I've made decisions] with that general ethical framework in mind" (Susan). The socialisation context of informants' moral life theme also cast an enduring influence over their selection of moral consumption life projects. For example, Carl's father owned and managed a small rural grocery store, and Carl's initial moral consumption life project was about shopping locally.

Informants' moral consumption life projects, however, were not the only life projects that they were consciously working on, and their moral life themes were not the only frameworks guiding their lives. We now present data illustrating the extension of multiplicity conflict to life projects and the life themes that guide them.

Extending multiplicity conflict to existential realms: multiple life themes guide multiple life projects 
Informants sensed that they are "juggling certain priorities" in their lives and that when these competing priorities intersect in the marketplace that "there aren't goods to meet all those things" (Adam). This balancing act highlights the complexities of everyday life that often result in the compromise of ethical concerns, as illustrated by Adam: "I am aware of the complexities of my particular situation because I live in a household with kids...and the realities of juggling lots of things in life get in the way; that is frustrating". Our informants were complex and multidimensional individuals. While their moral life theme was an important backdrop to their life, it isn't their only life theme, as Adam suggests: "There are a whole lot of spiritual dimensions [and] identity dimensions to consumption". Aligned with prior research (e.g. Mick and Buhl 1992), informants in our study displayed a number of life themes each, such as 'frugality', 'adventure', and 'status', in addition to 'moral'. These multiple life themes were juggled, prioritized and revealed as competing guiding frameworks in informants' many life projects such as career, parenthood, education and explicit consumption projects. For example, Mandy highlights her ongoing balancing act as she struggles to reconcile the many competing projects in her life.

"There are a few ethical concerns that I make decisions on and I have various levels of implementing them. [The] first one that I was concerned about from teenage years, or maybe even younger, was animal ethics. As a teenager I became vegetarian. I can say that continues to be one of my main ethical concerns and I make decisions based on that every day and I tend to follow that. Whereas some of my other ethical concerns it is about a balance of what fits in with me, what is realistic, what is achievable. I think it is - balance or compromise. It is just what you can realistically address, and I do balance a lot of different priorities all at once...Most people don't share the same concerns that I do. Most of my friends don't. In terms of eating out or things like that, I think that is where it becomes more difficult, because you do what your friends are doing, rather than making decisions that will be most in line with what you believe in".

The presence of multiple life themes threaded into multiple life projects and numerous visions of desired self, at times resulted in conflict and compromise in informants' consumption 
choices. While more apparent with informants at the early stages of their moral consumption life project, moral dilemma was universally evident and resulted in significant inconsistencies when other dimensions of informants' multifaceted self (such as being a parent) collided with their moral consumption life project in the marketplace. In these cases, when presented with a life theme, project or situational identity of greater immediate salience, morally compromised choices, moral conflict and dilemma often resulted. As Mandy suggests: "you have to make decisions all the time about what is more important to you". Two types of moral clashes were experienced by informants in consumption choices: (1) personal clashes between their own fragmented life themes and projects, and their moral selves; and (2) inter-personal clashes between their moral life themes/projects and the life themes prioritized in significant other's life projects.

Personal Life Theme and Life Project Clashes. Personal clashes occurred when life projects and identities that were dominated by other life themes crossed-over into 'consumption', creating consumption desires at odds with the informant's moral framework. For example, in discussions with Carl it became evident that his moral life theme was often at odds with a competing life theme of 'adventure', particularly in desired travel experiences incorporating carbon-intensive air travel. Eliza highlights the clashes between her moralistic and career life projects, which are informed by divergent life themes and enacted in consumption: "I think there is quite a bit of demand for tailored styled clothing in ethical fabrics, but enterprises just aren't addressing the demand. I found [an ethical] supplier but when I looked at their designs, you know I don't want to walk around work in what I describe as a hippy sack! - It's really frustrating”. This clashing of life projects was underpinned by the conflict between life themes jostling for prioritization. 
Inter-personal Life Theme and Life Project Clashes.

In a relationship, the dominant life themes of informants' partners were potential sources of consumption support through reinforcement and alignment, or conflict. Illustratively, Adam tells us that: "I was a vegetarian for 12 years, then I got married and made certain compromises". In the case of Nora and Paul, Nora suggests that "my partner is not at all inclined that way and he hasn't changed a bit since I met him...So I'm probably even more restricted in what I can do because of that, I have to compromise my values a lot". These compromises were evident in field notes from an accompanied shopping trip to the market and grocery store with Nora and Paul. The researcher observed these informants deliberating for some time over the choice of tomato pasta sauce and whether to buy the 'organic' variant or the cheaper product. Through-out the shopping trip, Paul displayed a dominant framework around being 'smart/frugal' with money, which crossed over both his consumption and career life projects (Paul is an accountant). In contrast, as an aspiring ethical consumer, Nora's ethical life theme had begun to consciously infiltrate her consumption and was also apparent in her recent decision to pursue graduate studies in sustainability. Nora ended up placing the organic tomato pasta sauce back on the shelf. A few aisles later, we stopped at the condensed milk, which Nora had on her list. Paul immediately said "look, three for six dollars", and Nora replied "but it's Nestlé".

The inter-personal clashes of life themes were externally derived, yet internally experienced by our informants as they juggled their momentarily competing moral and relationship life projects. Not all of our informants were capable of tolerating the tension arising from consumption choices in conflict with their moral life theme, whether navigating internally or externally derived conflict. We now explore this morally compromised multiplicity and conditions under which some informants could not manage the resulting tension. 
The Awakening: when morality in consumption becomes central to the self

Our study revealed that a number of informants had experienced an "awakening" (Adam), through which their moral life theme had become central to their sense of ideal self. Prior to this initial epiphany or triggering event, informant's moral life themes were just one of the life themes guiding their consumption choices, often focusing on other activities (e.g. volunteer and charity work) to express their guiding moral beliefs. This moralistic framework, however, became elevated to a heightened state of awareness and salience when the informant became aware of an ethical/moral issue linked with their consumption - for example, factory farming and their consumption of meat - that intensely resonated with their moral life theme. This issue awakened these informants to the realization that their own consumption, no matter how ineffectual, had been contributing to the moral harms they now found so abhorrent. As Sarah suggests, 'to connect my consumption, it's about awareness". To make the deep connection that would trigger an 'awakening', however, required a combination of "theoretical" and "practical" awareness (Carl) to: (1) initially construct the existential connection between consumption and informants' moral life theme; and (2) create an intimate link between their own consumption and tangible - and shocking - contributions to moral harm.

This awareness and resonance triggered a shift in their idealised conception of self, as they wove their moral frameworks and aligned consumption into the core of the person they would like to be. Monroe (2003, p 408) describes this initiation as a 'transformative encounter' that transforms a person's ideal self. In this sense, informants' idealised consumption self became fused to their moral framework (life theme) through this transformative encounter (Frimer and Walker 2009). Jessica's narration of her own awakening when becoming aware of the systems of apartheid in 
South Africa illustrates the intense resonance that this issue had with her moral guide and the subsequent shift in her sense of consumption self: "I think that really sparked my initial interest and I was shocked by the unfairness of the system and the terrible consequences for people. I think that led to my interest in trade and how consumption is quite a powerful tool to address those issues when people were talking about boycotting products from South Africa. I think that was my first introduction to consumerism as a tool."

The intense resonance of apartheid with Jessica's moral framework and her recognition of consumption as a means to exercise this moral life theme transformed her idealised self. This awakening embeds and elevates informants' moral life themes into the core of this idealised self. It was the elevation of their moral life theme to a standing of dominance that set these informants apart. We identify this as a dominant moral life theme.

\section{Dominant moral life theme.}

Armed with the vision to holistically "live my life as [ethically] as possible" (Rochelle), the moral life theme of these informants iteratively became a dominant life theme that guided their entire lifestyle: "it's become a life choice, it's a framework of being" (Sarah); "it's a lifestyle" (Carl). This dominant life theme was then used and prioritised as a guide for decision-making throughout the multiplicity of life and identity construction projects - consumption-based and otherwise. Sarah illustrates the centrality of her now dominant moral life theme to her life and self: "I don't think it's going 'Let's put the ethical lens on'. I think its inherent now: a very embedded frame in every kind of decision". This enhancement of informants' moral life theme to the dominant lens through which they filtered many of their life decisions is illustrated by Adam, Adele, Rochelle, 
Sarah, Carl and Nora who actively sought educational and career projects aligned with their moral life theme (see table 1).

Bahl and Milne (2010) discovered unresolved identity conflict arising from the domination of one identity over another, whereby the dominant voice of one identity silences the voice of the other identity. Similarly, though at a higher-order, the dominant moral life themes revealed in our study override the influence of other life themes - such as frugality and status - to take a position of overarching dominance in the creation of idealised self and the selection of life projects to obtain this life goal. Adele illustrates the encompassing and expansive influence of her now dominant moral life theme: "I'd like to think that it is about the way I live my life. That includes the big stuff and the - you know, changing the light-bulbs or whatever. For the things that I care about the most, then it informs the way I live..."

This finding differs from Bahl and Milne's (2010) interpretation, however, in that we discovered that informants' higher order dominant moral life theme magnified, rather than silenced, the conflict arising from multiplicity. As informants' moral life themes became woven into their core self, the sense of fractured moral self resulting from moral multiplicity conflict was now beyond the ability of coping mechanisms to create an illusion of self coherence.

\section{Unmanageable moral multiplicity}

As the now dominant moral life theme became the central filter through which they constructed and expressed their sense of ideal self, the tension resulting from contradictions to this life theme became unbearable for awakened informants. Susan articulates this heightened sense of discomfort when discussing her consumption contradictions: "I'm conscious of the contradictions in wanting to tread lightly on the earth and in fact not treading as lightly as I'd like to. That's an awareness 
that isn't comfortable". Similarly, Sarah tells of how "when I buy things that I know are ethically wrong...I do feel the dissonance and I'll have the fight with myself". Straying from their ethical consumption life projects, allowing other life themes to dominate and making compromising choices, leads to a sense of frustration, disappointment, resentment, guilt and regret for awakened consumers.

Aware that no matter how successful they were in consuming in alignment with their guiding moral life theme and how far they had progressed with their moral consumption project, informants' sensed that they were still making compromises against their ideal vision and making consumption decisions that were outside their guiding moral framework. "I feel guilty all the time...It would be great if I could feel in any way like I was doing as much as I can, and I don't feel that I am at the moment. I suppose that will take time" (Jessica). These compromises and trade-offs made informants feel discontent: "We're still on a journey because we're doing the best for where we are currently at, but we're not quite happy with it" (Adam). Similarly, Mandy describes the ongoing conflict between her ethically-based and other life priorities in the consumption space: "They are things [ethical concerns] that I am more and more conscious about now and try and make small steps of changing. But I still haven't completely changed my lifestyle to accommodate not purchasing those things. I have a constant battle with that every day".

Contravening their moral life theme and straying from their moral consumption project also evoked experiences of deep remorse, as illustrated by Sarah who purchased a smart phone under the influence of her career life project:

"You know what the authenticity is, you know what your truth is and it gets stronger. Falling away from it feels much worse than delaying gratification or going without. A few months ago, I purchased an iPhone, which I'd looked forward to. 


\begin{abstract}
About six weeks after I purchased it, I read about the manufacturer of iPhones. I have not used it since without a heavy heart. I've gotten this feeling of terrible regret. I feel resentful at myself that I went down that path."
\end{abstract}

In her narrative of profound conflict, Sarah also reveals the intensifying nature of her dominant moral life theme - greater alignment with this life theme increased its dominance ("it gets stronger"). While making everyday consumption choices aligned with their moral life theme gives informants a sense of "empowerment" (Jessica), conflicting decisions based upon other life themes (e.g. status, materialism) and life projects evoked a sense of deep "embarrassment and discomfort" (Jessica). Intense experiences of incoherence, frustration and regret associated with the moral compromises being made in their fragmented consumption lives, were outside of these informants' ability to ignore or manage through the deployment of coping strategies. Rather, these intense experiences of moral dilemma evoked a sense of unmanageable incoherence that led informants to attempt to eliminate, rather than manage, the source of moral conflict altogether, because as Sarah expresses, "when you are connecting with who you are, it feels like you are living your truth...that's just profoundly important. If we're not living our truth we can't be fully ourselves".

\title{
Transforming to a morally aligned self: meta life project of alignment
}

Intolerable experiences of incoherent moral self associated with making moral compromises led informants to embark on a journey of re-alignment that we have identified as a meta life project of alignment. This process of reconstruction was aimed at the realignment of their multiple life projects with the dominant moral life theme that for some informants had become so integrated into their vision of ideal self. Informants' meta life projects of alignment were focused on transforming their state of internal conflict and discord into one of equilibrium and moral self 
coherence. As Eliza suggests, “consuming ethically is satisfying because it's part of the piece of the puzzle of my life. It fits. I experience more emotion when I can't [shop ethically] - frustration and disappointment”.

The meta life project of alignment is 'meta' in an epistemological sense - a 'project about/of projects' - rather than on a higher level of abstraction to informants' other life projects. In this sense, the meta life project of alignment appeared to act as a magnetic force, drawing in informants' other life projects - such as parenthood, education and career - and binding them to their dominant moral life theme. Moral consumption becomes a holistic life choice and life journey: "my whole life needs to reflect what I value" (Adele). Thus, embarking upon and traversing the meta life project of alignment is about reconstituting one's sense of self and constructing a new, whole self upon a dominant moral framework. Illustrating this holistic and iterative transition, Rochelle tells us that: “There's a long way to go, I'm still at the beginning points...I'm not [yet] living a completely sustainable lifestyle, but it's my intention”.

The alteration in informants' sense of ideal or desired self also generated an awareness of the inconsistencies between their current consumption practices and their moral consumption self. Awareness of the inconsistencies creates a sense of discontent, fuelling continued work and progression on the meta life project. Adam discusses: "going quite deliberately out of my way to think about the impacts of my purchases and what I value, and then making sure that they are aligned". At a symbolic level, Adam's meta life project is about closing the 'gap' between actual self and ideal moral self.

Thus, starting as a moral consumption life project in amongst other life projects, this project expanded considerably to become a meta life project of alignment directed at living a coherent moral life. As work continued on the meta life project of alignment, this project expanded to 
include other elements of informants' whole life in response to a sense of internal discord and a desire for a coherent moralistic self concept. The ultimate goal was to live an entirely moral life in every dimension. Adam describes both his broad vision of ideal moralistic life, self and society, as well as his conception of the meta life project.

“On a broader level, is cultural change and it can happen and we've seen little glimpses of it, but they're glimpses, and so there is a huge need for cultural change. Really it's about redefining who we are...there are lots of different elements to the goal. I suppose cultural change in whatever form it takes, is the goal, individual change, change on lots of levels, but us all moving in a certain direction. I think we [Adam and his wife] are successful in the sense that our goals are changing and are getting bigger. We're a long way along a path and therefore I think we are doing really, really well. But it is easier as we go along. You start with what you can do and start there and move forward and it's going to be far from perfect: your pantry is going to be a mix of all sorts of things. It's a huge journey."

This visualized end destination - ideal self - provides a sense of purpose, direction and meaning. Informants sensed that their ideal vision, however, was "far in the future" (Jessica) and that they were on a journey "working towards" (Peta) this goal - "so you have to work to towards being at the far end, where you really have integrity in all of your decision making and behavior" (Eliza).

Binding multiple life projects to their expanding meta life project created a pathway of moral alignment along which some informants progressively gained an increasingly coherent sense of actual and ideal moral self. For example, Adele illustrates the infiltration of her moral life theme into her career life project when she attended an 'environmental' workshop being facilitated by a friend in 1997: "I thought that's exactly what I want to do. That's it... Then it just escalated from there, after I felt there was somewhere for me to express my [concerns]. After that, I went back to 
uni and did a post-grad diploma and started working in environmental education and waste management."

As informants progressed further on this meta life project of alignment, they also became less prepared to tolerate inter-personal market-based moral clashes with their friends or partners; actively influencing others to also embark on similar ethical consumption journeys and/or selecting friends and partners who already aligned with their moral life themes and consumption concerns. For example, Rochelle homemade many of her gifts, such as a hand scrub that she made from lemons grown in her garden, to both project her extended moral self and to influence others.

Work on the meta life project of alignment includes the discarding of misaligned life projects and life themes as well as the development of new and aligned life projects. This gradual transition towards a more coherent moral self is expressed in increasingly consistent consumption practices. Progression on the meta life project of alignment tended to be gradual because it requires conscious effort and it is difficult. Susan demonstrates the difficulties and long-term commitments of her meta life project: "Certainly on ongoing consumer stuff that I buy week in week out and have been buying for 20 years, I think I've become relatively successful at not making any compromises. It takes time because it's not easy...to change what you buy regularly week in week out, I think is difficult. And, any changes I've made have been gradual and then it feels comfortable. It's just what I do then."

This gradual alignment resulted in reduced experiences of moral tension and moral compromises. Transitioning on the meta life project gave these informants a sense that their moral framework had become a "part of how I live...it's easy and I love it...it means that my beliefs are integrated into the way I live" (Susan). We illustrate this process of transformation to reconstruct a coherent moral self in Figure 1. 


\section{INSERT FIGURE 1 HERE}

We now discuss the implications of this meta life project of alignment and our other findings to the extant multiplicity, morality, and life project literatures.

\section{Discussion}

The life worlds of consumers who seek to consume ethically provide a powerful vantage point from which to view multiplicity and contradictory consumption in the moral domain. We find that consumers' experiences of self may become incoherent when two or more life themes are morally at odds. These contradictory life themes guide multiple, conflicting life projects that are expressed through juxtaposed identities and extended selves in the marketplace. Schouten (1991) suggests that the consistency of consumption choices plays a critical role in consumers' experiences of psychological cohesion, and we extend this to the moral domain.

This study makes five contributions to marketing research and practice. First, we extend conceptions of identity multiplicity by illustrating that identity multiplicity conflict is derived from clashing higher-order life projects and life themes. Second, we build on previous theorisations of multiplicity as either liberating (e.g. Firat, Dholakia and Venkatesh, 1995) or managed through coping strategies (Bahl and Milne, 2010), with the discovery that some consumers experience unmanageable tension when faced with moral dilemmas that compromise their sense of moral self. Third, we show how moral life themes underpin a process of transformation - the meta life project - to attain moral self coherence. Fourth, we theorise an enriched explanation of consumer experiences of moral dilemma and the widely documented 'ethical consumption gap'. Finally, we 
offer policy and marketing practice implications arising from this research. We now extend our discussion of these contributions.

\section{Extending Multiplicity Beyond Identity}

Our extrapolation of the roles of life themes and life projects extends previous conceptualization of identity multiplicity. Consumers' multiple identities are activated by situational cues (Markus and Nurius, 1986; Monroe, 2003; Schouten, 1991; Bardhi et al., 2012), where identity is the sense of 'who I am' at this moment and in this situation (Callero, 2003). Our study demonstrates that situationally evoked identities may prompt consumption choices that are either aligned with, or contrary to, any number of the various life projects being navigated and overarching life themes held by the individual. For example, while Adam's moral life theme played an important role in defining his fatherhood life project, other life themes such as nurture and experience were also threaded into his construction of ideal father. Adam also expressed various identities and overlapping life projects regarding activist, ethical consumer, educator, bread winner, son, and husband, which were each connected to multiple life themes. This multiplicity results in clashes and compromises, within the context of a single life and self.

The transformation of self is conceived in consumer research through consumer life projects (McCracken, 1987; Mick and Buhl, 1992; Schau et al., 2009; Schouten and McAlexander, 1995). Life projects are directed towards an end goal of idealised self and lifestyle (Arnould and Thompson, 2005; Markus and Nurius, 1986, Schau et al., 2009). The selection of this ideal self from the set of possible selves (Belk, 1988), is guided by one's own set of overarching life themes. Thus, life themes, life projects, and ideal self are inextricably linked. This gives rise to the possibility that an individual can be motivated in multiple directions and be simultaneously 
working on multiple discordant pathways of self transformation simultaneously. These complex layers of plurality conceptually open the door to the higher-level multiplicity conflict evident in our study.

This multi-layered, multi-dimensional conception of consumers' heterogeneous life worlds extends current understanding of the multiplicity and contradiction inherent to consumption in modernity from identity to the higher-order life projects and life themes. This extended conception of multiplicity and layers of interplay provides insight into why multiplicity conflict and the resulting moral dilemma can create an intolerable sense of moral incoherence and threatened existential security (Ustuner and Holt, 2007; Giddens, 1991). This analysis also extends the conceptualisation of identity construction within the ethical consumption literature (e.g. Cherrier, 2007; Brace-Govan and Binay, 2010; Niinimaki 2010) to show that these identity transformations are guided by higher-order life projects and life themes and are enmeshed in complex layers of self multiplicity; illustrating the limitations of studying a singular identity in isolation. This finding also sheds light on the tensions arising from sites of normative conflict, such as Guilliard and Roux's (2014) study of disposers and gleaners.

\section{Unmanageable Multiplicity and the Discordant Moral Self}

Unlike previous research that has suggested that identity multiplicity may be liberating (Firat and Venkatesh, 1995) or manageable (Bahl and Milne, 2010), we found that moral discord can be unmanageable. Our study reveals a moral life theme that is often initially dormant in the marketplace, yet active in other spheres of life, such as parenting life projects. Monroe (2009) posits that a guiding moral framework is an inherent human trait; we are all born with a latent moral perspective waiting to be activated. Whether or not we activate and embed this moral 
framework into our sense of self and daily practices, however, is dependent upon the existence of conditions - such as the availability of information - to serve as "triggers" (Monroe, 2009, p 422). Our findings resonate with Monroe's focus on the socialization of moral life themes through family role-models in early life and the availability of information throughout life. Role-models (parents and grandparents) tended to express their moral life themes in other spheres such as through their volunteering and religious practices - previously sacred domains (Belk et al., 1989). The transference of what is sacred in modern consumption society (Belk et al., 1989), coupled with an increasing visibility and awareness of the ethics embedded in consumption, led informants to also express their moral life themes in the marketplace.

Moral frameworks rose to a heightened position of dominance in the marketplace when these informants experienced an epiphany, or 'awakening', that triggered a self-awareness of the consequences of their consumption. This finding extends notions of existential crisis points resulting from consumer awareness of ethical issues explored in the voluntary simplicity literature (e.g. Shaw and Newholm, 2002; Zavestoski, 2002), to reveal that to trigger this self-awareness requires the dual construction of: (1) an existential connection between consumption and moral life theme; and (2) an intimate - and shocking - link between personal consumption and abhorrent moral harm.

Once awakened to a higher level of awareness, the commitment to consuming morally in the issue of concern (e.g. animal welfare), results in a re-evaluation of the ideal self (Kleine and Kleine, 2000) expressed in the marketplace. Once triggered, this moral perspective becomes dominant, and is increasingly integrated into the sense of self and life choices (Monroe, 2009; Monroe, 2003; Frimer and Walker, 2009). This process of integration limits consumers' ability to cope with discord created by moral clashes in multiplicity. Thus, it seems that consumers' 
experience of liberation (e.g. Firat and Venkatesh, 1995) or coping with moral conflict (e.g. Bahl and Milne, 2010) is contingent upon the absence of a dominant moral life theme expressed in the marketplace. Further research is needed, however, to explore whether this mechanism is limited to moral life themes, or, if other life themes - such as status or healthy living - can become dominant under the right conditions.

\section{Transitions of Alignment, Integration and Coherence - The Meta Life Project}

Our study reveals a mechanism of transformation through which 'awakened' consumers iteratively eliminate sources of multiplicity and moral conflict. Our study reveals that, once integrated into the self, the dominant moral life theme becomes an irresistible magnet, drawing all life projects towards it in a process of moral self re-unification. This process of moral self re-unification provides a pathway to the resolution, rather than management, of moral conflict in consumption contexts, and is represented by the meta life project.

Where McCracken (1987) suggests that singular life projects involve the harmonious integration of selected notions into a single self and life, our study reveals a meta life project that involves the integration of a single dominant life theme into self and life to re-unify moral self in the midst of modern heterogeneous life. Through this meta life project, many life projects (e.g. community activism, parenthood and career) and related situational identities are iteratively fused to the dominant moral life theme. The end goal of this meta life project - an ideal vision of a coherent moral self - increasingly becomes the lens through which many life projects are viewed and situational role identities are selected.

It is through this notion of dynamic alignment around a singular life theme, that this study expands the literature to show that transitions of the whole self involve the evolution of a complex 
and layered collection of supporting life projects and identities that must be balanced, negotiated and directed. Without the guide of an overarching dominant framework (life theme), the sense of moral coherence - or freedom (Dobscha and Ozanne, 2001) - sought by the awakened consumer cannot be attained, and morally guided life projects remain discrete and somewhat disorganised (Newholm, 2005).

The study also reveals that as much as the ethical life projects of informants were directed at constructing a transformed life and self (Schouten and McAlexander, 1995), their life projects were equally about moving away from and deconstructing past lives and selves now unwanted. Life project work requires the shedding of old selves (Kleine et al., 1995), layer by layer, and the disconnection from old lifestyles. In this light, this study further expands Schau et al.'s (2009) conception of life projects as iterative and non-linear to containing a dichotomy of 'former selves living undesired lives' versus 'ideal future self living the good life'. We found that for those consumers just beginning a particular life project, the force of repulsion away from the undesired self/life is often stronger than the pull towards an ideal self/life, which may still be vague and unformed. In the ethical consumption context, this finding extends Hogg, Banister and Stephenson's (2009) conceptualisation of anti-consumption as being linked to the projection of undesired self (Markus and Nurius 1986), where the inter-relationship between undesired self and distaste leads to rejection and avoidance.

\section{Enriching Understanding of Moral Dilemma and the Ethical Consumption 'Gap'}

Our study extends current morality theory in consumer studies to consider consumer experiences of moral conflict waged on internal stages and across the multiple domains of daily life inherent to late modernity. Extending Saatcioglu and Ozanne's (2013) static notion of moral habitas, we 
show that as consumers dynamically move between their multiple life domains, context derived moral frameworks can also pose in-the-moment tension and incoherence. Our study also reveals that Weinberger and Wallendorf's (2012) notion of social cohesion through the interplay of moral and market economies is contingent on the absence of an awareness of a moral dilemma when these economies intersect.

Furthermore, the study illuminates an underlying dynamic in the extent to which consumers consistently shop with their moral guides. We show that the consumption contradictions of ethically concerned consumers are more pronounced for consumers who are yet to experience a trigger/epiphany that shifts their vision of ideal self to rest on a moral core. In the absence of a dominant moral life theme, these consumers are able to deploy coping strategies - such as neutralization techniques (Chatzidakis et al., 2007) - to manage their ongoing consumption dilemmas. Further, extending notions of existential crises and inauthentic consumption as drivers of anti-consumption and voluntary simplicity practices (Shaw and Newholm, 2002; Zavestoski, 2002; Cherrier et al., 2011), our research provides an enriched understanding of the moral tensions created in the struggle to reconcile contradictory consumption desires and the role that this discord plays in the purposive transition to a more coherent self.

\section{Implications for Social Policy and Marketing Practice}

McDonagh and Prothero (2014) call for marketing research that "considers how we change the consumption ideology" and "utilise various marketing tools and techniques" (p 1201) towards more sustainable and ethical consumption practices. In Table 2, we offer potential implications of the study which we hope will be helpful for future research, public policy, and marketing practice. 
INSERT TABLE 2 HERE 


\section{References}

Ahuvia, A. C. (2005) Beyond the Extended Self: Loved Objects and Consumers' Identity Narratives. Journal of Consumer Research, 32, 171-184.

Arnould, E. \& Thompson, C. (2005) Consumer Culture Theory (CCT): Twenty Years of Research. Journal of Consumer Research, 31, 868-662.

Arnould, E. \& Wallendorf, M. (1994) Market-Oriented Ethnography: Interpretation Building and Marketing Strategy Formulation. Journal of Marketing Research, 31, 484-504.

Bahl, S. \& Milne, G. R. (2010) Talking to Ourselves: A Dialogical Exploration of Consumption Experiences. Journal of consumer Research, 37, 176-195.

Bardhi, F., Eckhardt, G. M. \& Arnould, E. J. (2012) Liquid Relationships to Possessions. Journal of Consumer Research, 39.

Barnett, Clive, Philip Cafaro, and Terry Newholm (2005) Philosophy and Ethical Consumption. IN Rob Harrison, Terry Newholm and Deirdre Shaw ed., The Ethical Consumer, London, Sage Publications Ltd.

Bauman, Z. (2013) Liquid Modernity, Hoboken, Wiley.

Belk, R. (1988) Possessions and the Extended Self. Journal of Consumer Research, 15, 139-168.

Belk, R., Devinney, T. M. \& Eckhardt, G. (2005) Consumer Ethics Across Cultures. Consumption, Markets and Culture, 8, 275-289.

Belk, R., Wallendorf, M. \& Sherry JR., J. F. (1989) The Sacred and the Profane in Consumer Behavior: Theodicy on the Odyssey. Journal of Consumer research, 16, 1 - 38.

Belk, R. W. \& Costa, J. A. (1998) The Mountain Man Myth: A Contemporary Consuming Fantasy. Journal of Consumer Research, 36, 715-734. 
Bennett, A. M., Hill, R. P. \& Oleksiuk, D. (2013) The Impact of Disparate Levels of Marketplace Inclusion on Consumer-Brand Relationships. Journal of Public Policy \& Marketing, 32, 16-31.

Brace-Govan, J. \& Binay, I. (2010) Consumption of Disposed Goods for Moral Identities: A Nexis of Organisation, Place, Things and Consumers. Journal of Consumer Behaviour, 9, 69-82.

Brewer, M. B. (2001) The Many Faces of Social Identity: Implications for Political Psychology. Political Psychology, 22, 115-125.

Callero, P. L. (2003) The Sociology of the Self. Annual Review of Sociology, 29, 115-133.

Carrington, M. J., Neville, B. A. \& Whitwell, G. J. (2014) Lost in translation: Exploring the ethical consumer intention-behavior gap. Journal of Business Research, 2759.

Chatzidakis, A., Hibbert, S. \& Smith, A. P. (2007) Why People Don't Take their Concerns about Fair Trade to the Supermarket: The Role of Neutralisation. Journal of Business Ethics, 74, 89-100.

Chatzidakis, A. \& Lee, M. (2013) Anti-consumption as the reasons against. Journal of Macromarketing, 33, 190-203.

Cherrier, H. (2007) Ethical Consumption Practices: Co-production of self-expression and social recognition. Journal of Consumer Behaviour, 6, 321-335.

Cherrier, H. (2009) Anti-Consumption Discourses and Consumer-Resistant Identities. Journal of Business Research, 62, 181-90.

Cherrier, H., Black, I. \& Lee, M. (2011) Intentional non-consumption for sustainability: Consumer resistance and/or anti-consumption? European Journal of Marketing, 45(1112), 1757-1767. 
Connolly, J. \& Prothero, A. (2008) Green Consumption: Life-politics, Risk, and Contradictions. Journal of Consumer Culture, 8, 117-145.

Corbin, J. \& Strauss, A. (2008) Basics of Qualitative Research, Thousand Oaks, California, SAGE Publications.

Crane, A. \& Matten, D. (2004) Business Ethics: A European Perspective, Oxford, Oxford University Press Inc.

Crane, A. \& Matten, D. (2010) Business Ethics, New York, Oxford University Press Inc.

De Pelsmacker, P. \& Janssens, W. (2007) A Model for Fair Trade Buying Behaviour: The Role of Perceived Quantity and QUality of Information and Product-specific Attitudes. Journal of Business Ethics, 75, 361-380.

Dobscha, S. \& Ozanne, J. L. (2001) An Ecofeminist Analysis of Environmentally Sensitive Women Using Qualitative Methodology: The Emancipatory Potential of an Ecological Life. American Marketing Association.

Firat, A. F., Dholakia, N. \& Venkatesh, A. (1995) Marketing in a Postmodern World. European Journal of Marketing, 29, 40-56.

Foucault, M. (1992) On the Genealogy of Ethics: An Overview of Work in Progress. IN Rabinow, P. (Ed.) The Foucault Reader. London and New York, Penguin Books.

Frimer, J. A. \& Walker, L. J. (2009) Reconciling the Self and Morality: An Empirical Model of Moral Centrality Development. Developmental Psychology, 45, 1669-1681.

Giddens, A. (1990) The Consequences of Modernity, Cambridge, MA, Polity.

Giddens, A. (1991) Modernity and Self-Identity: Self and Society in the Late Modern Age, Stanford, CA, Stanford University Press. 
Goulding, C., Shankar, A. \& Elliott, R. (2002) Working Weeks, Rave Weekends: Identity Fragmentation and the Emergence of New Communities. Consumption, Markets and Culture, 5, 261-284.

Goulding, C., Shankar, A., Elliott, R. \& Canniford, R. (2009) The Marketplace Management of Illicit Pleasure. Journal of Consumer Research, 35, 759-771.

Guillard, V. \& Roux, D. (2014) Macromarketing Issues on the Sidewalk: How "Gleaners" and "Disposers" (Re)Create a Sustainable Economy. Journal of Macromarketing, 34, 291312.

Hammersley, M. \& Atkinson, P. (2008) Ethnography - Principals in Practice, London, Routledge.

Harper, G. C. \& Makatouni, A. (2002) Consumer Perception of Organic Food Production and Farm Animal Welfare. British Food Journal, 104, 287-99.

Heelas, P., Lash, S. \& Morris, P. (1996) Detraditionalization : critical reflections on authority and identity / edited by Paul Heelas, Scott Lash, and Paul Morris, Cambridge, Mass. : Blackwell Publishers, 1996.

Hogg, M. K., Banister, E. N., \& Stephenson, C. A. (2009) Mapping symbolic (anti-) consumption. Journal of Business Research, 62, 148-159.

Kilbourne, W. E. \& Beckmann, S. C. (1998) Review and Critical Assessment of Research on Marketing and the Environment. Journal of Marketing Management, 14, 513-32

Kleine, R. E. \& Kleine, S. S. (2000) Consumption and Self-Schema Changes Throughout the Identiy Project Life Cycle. Advances in Consumer Research, 27, 279-285. 
Kleine, S. S., Kleine, R. E. \& Allen, C. T. (1995) How Is a Possession "Me" or "Not Me"? Characterizing Types and an Antecedent of Material Possession Attachment. Journal of Consumer Research, 22, 327-343.

Kozinets, R. (2002) Can Consumers Escape the Market? Emancipatory Illuminations from Burning Man. Journal of Consumer Research, 29, 20-38.

Kozinets, R. \& Handelman, J. (2004) Adversaries of Consumption: Consumer Movements, Activism, and Ideology. Journal of Consumer Research, 31, 691-704.

Lincoln, Y. A. \& Guba, E. G. (1985) Naturalistic Inquiry, Beverly Hills, Sage.

Luedicke, M. K., Thompson, C. J. \& Giesler, M. (2010) Consumer Identity Work as Moral Protagonism: How Myth and Ideology Animate a Brand-Mediated Moral Conflict. Journal of Consumer Research, 36, 1016-1032.

Marcus, G. (1995) Ethnography in/of the world system: The emergence of Multi-Sited Ethnography. Annual Review of Anthropology, 24, 95-117.

Markus, H. \& Nurius, P. (1986) Possible Selves. American Psychologist, 41, 954-969.

McCracken, G. (1987) Advertising: Meaning or Information? Advances in Consumer Research, $14,121-124$.

McDonagh, P. (1998) Towards a Theory of Sustainable Communication in Risk Society: Relating Issues of Sustainability to Marketing Communications. Journal of Marketing Management, 14, 591-622

McDonagh, P. \& Prothero, A. (2014) Sustainability marketing research: past, present and future. Journal of Marketing Management, 1186. 
McGraw, A. P., Schwartz, J. A. \& Tetlock, P. E. (2012) From the commercial to the communal: reframing taboo trade-offs in religious and pharmaceutical marketing. Journal of Consumer Research, 157.

Mick, D. G. \& Buhl, C. (1992) A Meaning-based Model of Advertising Experiences. Journal of Consumer Research, 19, 317-338.

Miles, M. \& Huberman, A. (1994) Qualitative Data Analysis: A Sourcebook of New Methods, Newbury Park, CA, Sage.

Monroe, K. (2003) How Identity and Perspective Constrain Moral Choice. International Political Science Review, 24, 405-425.

Monroe, K. R. (2009) The Ethical Perspective: An Identity Theory of the Psychological Influences on Moral Choice. Political Psychology, 30, 419-444.

Newholm, T. (2005) Case Studying Ethical Consumers' Projects and Strategies. IN Harrison, R., Newholm, T. \& Shaw, D. The Ethical Consumer, London, Sage Publications Ltd.

Newholm, T. \& Shaw, D. (2007) Studying the Ethical Consumer: A Review of Research. Journal of Consumer Behaviour, 6, 253-70.

Nicholls, A. \& Lee, N. (2006) Purchase decision-making in fair trade and the ethical purchase 'gap': 'is there a fair trade twix?'. Journal of Strategic Marketing, 14, 369-386.

Niinimaki, K. (2010) Eco-Clothing, Consumer Identity and Ideology. Sustainable Development, $18,150-62$.

Saatcioglu, B. \& Ozanne, J. L. Moral Habitus and Status Negotiation in a Marginalized Working-Class Neighborhood. Journal of Consumer Research, 40, 692-710. 
Schau, H. J., Gilly, M. C. \& Wolfinbarger, M. (2009) Consumer Identity Renaissance: The Resurgence of Identity-Inspired Consumption in Retirement. Journal of Consumer Research, 36, 255-276.

Schouten, J. W. (1991) Selves in Transistion: Symbolic Consumptions in Personal Rites of Passage and Identity Reconstruction. Journal of Consumer Research, 17, 412-425.

Schouten, J. W. \& McAlexander, J. H. (1995) Subcultures of Consumption: An Ethnography of the New Bikers. Journal of Consumer Research, 22, 43-61.

Shaw, D. \& Connolly, J. (2006) Identifying Fair Trade in Consumption Choice. Journal of Strategic Marketing, 14, 353-68.

Shaw, D. \& Newholm, T. (2002) Voluntary Simplicity and the Ethics of Consumption. Psychology \& Marketing, 19, 167-185.

Shaw, D. \& Shiu, E. (2002) The Role of Ethical Obligation and Self-Identity in Ethical Consumer Choice. International Journal of Consumer Studies, 26, 109-16.

Smith, N. C. (2008) Consumers as Drivers of Corporate Social Responsibility. IN Crane, A., McWilliams, A., Matten, D., Moon, J., \& Siegel, D. S. eds. The Oxford Handbook of Corporate Social Responsibility, Oxford, Oxford University Press.

Spiggle, S. (1994) Analysis and Interpretations of Qualitative Data in Consumer Research. Journal of Consumer Research, 21, 491-503.

Szmigin, I., Carrigan, M. \& McEachern, M. G. (2009) The Conscious Consumer: Taking a Flexible Approach to Ethical Behaviour. International Journal of Consumer Studies, 33, 224-31.

Thompson, C. J. (1996) Caring Consumers: Gendered Consumption Meanings and the Juggling Lifestyle. Journal of Consumer Research, 22, 388-407. 
Tian, K. \& Belk, R. W. (2005) Extended Self and Possessions in the Workplace. Journal of Consumer Research, 32, 297-310.

Ustuner, T. \& Holt, D. B. (2007) Dominated Consumer Acculturation: The Social Construction of Poor Migrant Women's Consumer Identity Projects in a Turkish Squatter. Journal of Consumer Research, 34, 41-56.

Varman, R. \& Belk, R. W. (2009) Nationalism and Ideology in an Anticonsumption Movement. The Journal of Consumer Research, 36(4), 686-700.

Wallendorf, M. \& Belk R. W. (1989) Assessing Trustworthiness in Naturalistic Consumer Research. In Hirschman, E. C. (Ed.) Interpretive Consumer Research. Provo, UT, Association for Consumer Research.

Weinberger, M. F. \& Wallendorf, M. (2012) Intracommunity gifting at the intersection of contemporary moral and market economies. Journal of Consumer Research, 229.

Zavestoski, S. (2002) The social-psychological bases of anticonsumption attitudes. Psychology and Marketing, 19, 149-165.

\footnotetext{
${ }^{\mathrm{i}}$ Triple bottom line refers to the three pillars of sustainability: social, environmental and economic.
} 


\section{FIGURE 1}

Meta Life Project of Alignment

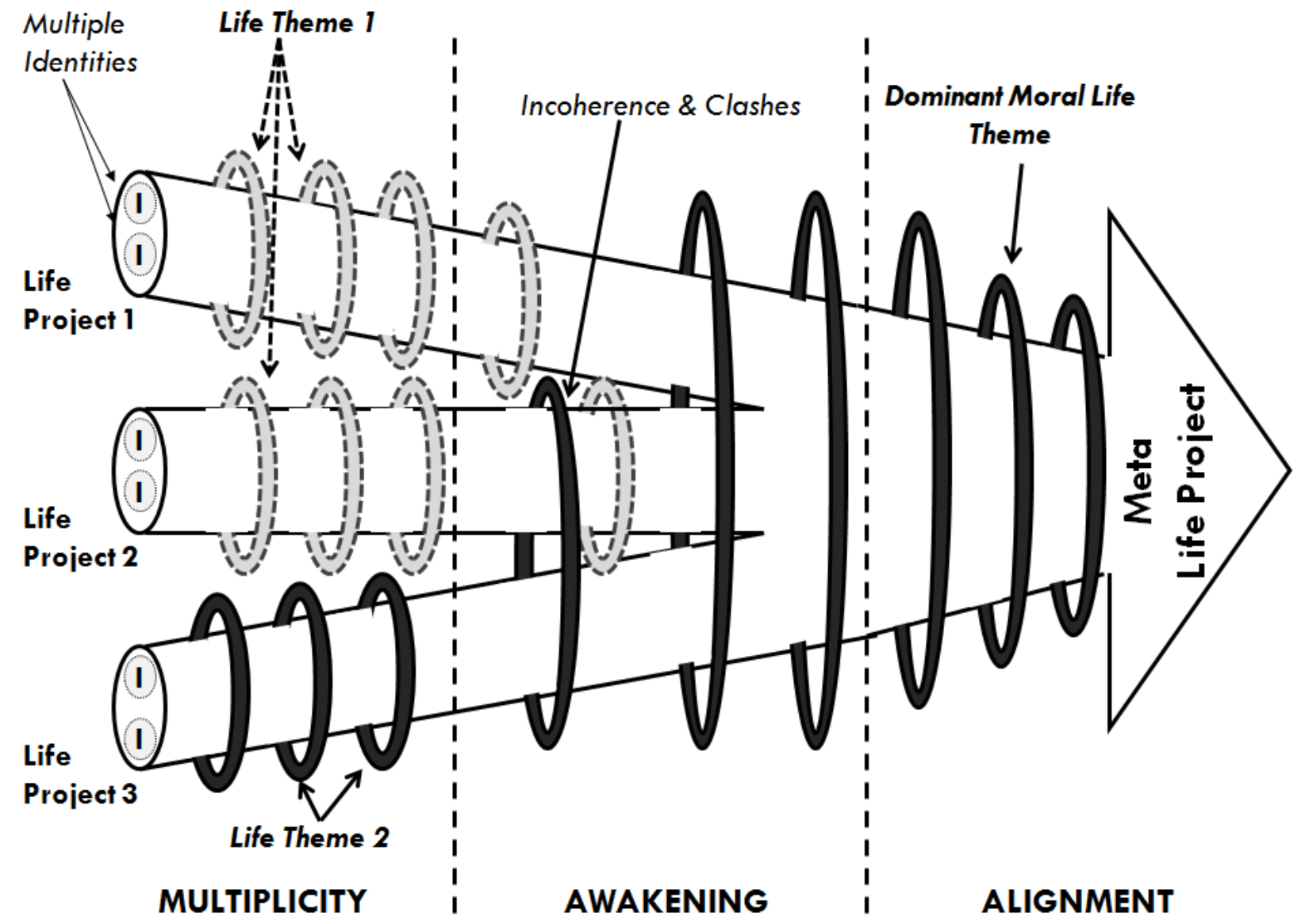


TABLE 1

\begin{tabular}{|c|c|c|c|}
\hline Pseudonym & Generation & Occupation & Partner / Family \\
\hline Adam & Gen $X$ & $\begin{array}{l}\text { (a) Local Government - waste } \\
\text { collection program }(\mathrm{P} / \mathrm{T}) \text {. } \\
\text { (b) Coordinates an ethical } \\
\text { consumer network (volunteer) }\end{array}$ & Married, 2 children \\
\hline Adele & Gen X & $\begin{array}{l}\text { (a) Local Government - } \\
\text { sustainability (F/T) } \\
\text { (b) Coordinates an environmental } \\
\text { awareness group (volunteer) }\end{array}$ & Long-term partner \\
\hline Rochelle & Gen Y & NGO - sustainability $(\mathrm{F} / \mathrm{T})$ & Single \\
\hline Sarah & Gen $X$ & $\begin{array}{l}\text { Educator (Higher Ed.) - } \\
\text { Sustainability }(\mathrm{F} / \mathrm{T})\end{array}$ & Married, 1 child \\
\hline Eliza & Gen $X$ & Undisclosed & Married \\
\hline Susan & $\begin{array}{l}\text { Baby } \\
\text { Boomer }\end{array}$ & $\begin{array}{l}\text { (a) Educator (retired) } \\
\text { (b) Coordinates a local community } \\
\text { cooperative agriculture group } \\
\text { (volunteer) }\end{array}$ & $\begin{array}{l}\text { Married, grown-up } \\
\text { children }\end{array}$ \\
\hline Peta & $\begin{array}{l}\text { Baby } \\
\text { Boomer }\end{array}$ & Consultant (F/T) & $\begin{array}{l}\text { Married, grown-up } \\
\text { children }\end{array}$ \\
\hline Carl & Gen $X$ & Government - Sustainability $(\mathrm{F} / \mathrm{T})$ & Single \\
\hline Jessica & Gen $\mathrm{X}$ & Researcher $(\mathrm{F} / \mathrm{T})$ & Married, 1 child \\
\hline Mandy & Gen $X$ & Dietician $(\mathrm{P} / \mathrm{T})$ & Single \\
\hline Nora & Gen Y & Government - Sustainability $(\mathrm{F} / \mathrm{T})$ & Long term partner \\
\hline Paul & Gen Y & Accountant $(\mathrm{F} / \mathrm{T})$ & Long term partner \\
\hline Alex & Gen $Y$ & Government-Finance (F/T) & Single \\
\hline
\end{tabular}


TABLE 2

\begin{tabular}{|c|c|}
\hline Study Contributions & Implications for Policy and Social Intervention \\
\hline $\begin{array}{l}\text { 1. Multiplicity extends beyond } \\
\text { identity }\end{array}$ & $\begin{array}{l}\text { The sites of life theme socialisation represent idea } \\
\text { locations for public policy and intervention. This } \\
\text { study illustrates the importance of family role }\end{array}$ \\
\hline Literature Implication and & models - parents and grandparents - in the \\
\hline Extension: consumer identity & socialisation of life themes, including moral life \\
\hline multiplicity (e.g. Bardhi et al., & themes that then play a determinant role in \\
\hline 2012; Bahl and Milne, 2010); & ongoing life and consumption choices of the \\
\hline $\begin{array}{l}\text { consumer transitions } \\
\text { projects, and life the }\end{array}$ & es of \\
\hline Schouten and Alexander, 1995; & $\begin{array}{l}\text { early life theme socialisation may have a lasting } \\
\text { and significant impact on the salience of morality }\end{array}$ \\
\hline Schau et al., 2009; Mick and & - or other desired life themes - in consumption \\
\hline Buhl, 1992). & choices. \\
\hline
\end{tabular}

2. Multiplicity and the Discordant Moral Self

Literature Implication and Extension: liberated multiplicity (e.g. Firat and Venkatesh, 1995; Goulding et al., 2009); managed multiplicty(e.g. Bahl and Milne, 2010; Luedicke, Thompson and Giesler, 2010); moral self (e.g. Monroe, 2009; Hitlin 2011;

Saatcioglu and Ozanne 2013); voluntary simplicity (e.g. Shaw and Newholm 2002).
The 'awakening' event illustrates the importance of developing policy and social messages that are personalised in nature and enable the consumer to make an intimate connection between their own consumption and moral harm that they find personally abhorrent and shocking. This implication may assist to explain why some consumers respond so strongly to local animal welfare messages - such as local campaigns against caged chickens, and yet can distance themselves from the global social or environmental impacts of their consumption.

\section{Implications for Marketing Practice}

Fluidity and contradiction are central to consumers' experience and life in modernity. Marketing managers can assist consumers to navigate the resulting conflict by anticipating that: (1) individuals are juggling multiple existential concerns (life themes); and (2) the salience of each 'life theme' can be momentary and situationally evoked. These insights direct marketing managers away from normative and universal approaches to influencing moral/ethical consumption outcomes, in favor of nuanced and fluid approaches that move and transition with consumers through their momentary and situational experiences of daily life.

Marketing managers can create stimulus and events that act as 'triggers' or moments of 'awakening' central to changing consumption practices permanently and sustainably. To be effective 'triggers', marketing communication and activities need to have a dual focus to: (1) broadly connect consumption with existing moral life themes; and (2) create a 'shock' moment where the consumer intimately recognises that their own consumption is contributing to abhorrent, salient, and very real moral harms. 


\section{Transitions of Alignment, Integration and Coherence}

Literature Implication and

Extension: consumer transformation (e.g. McCracken, 1987; Schouten and

McAlexander, 1995; Schau et al., 2009); consumer coherence (e.g. Schouten, 1991).

\section{Enriched Understanding of} Moral Dilemma and the Ethical/sustainable Consumption 'Gap'.

Literature Implication and Extension: morality and the marketplace (e.g. Saatcioglu and Ozanne, 2013; Weinberger and Wallendorf, 2012); ethical consumption (e.g. Shaw and Shui, 2003; Szmigin et al., 2009;

Carrington et al., 2014); voluntary simplicity and anti-consumption (e.g. Zavestoski, 2002; Cherrier et al., 2011).
Public policy makers and social enterprises can intervene to provide consumers with practical tools to facilitate progress on their meta life project and enable them to enmesh their multiple life projects - such as career and parenting - to their dominant moral life theme. Thus, aligning consumption choices across life domains to regain a sense of moral self coherence, with well-being outcomes for the individual, and positive social and environmental outcomes more broadly. In addition, recognising that this transition is about closing the 'gap' between actual self and ideal moral self may provide an effective platform for communication.

Consumer response to a moral dilemma arising from multiplicity conflict in the marketplace hinges on the intensity of the experience for the individual consumer, and these experiences of conflict can vary from moment to moment. While in one situation a consumer shops ethically in accordance with their moral code, yet in another context the same consumer displays an ethical 'gap' as other life themes and projects are momentarily more salient. This insight has implication for policy and marketing practice alike: (1) understanding that the salience of specific issues can be situationally variable as individuals move through the many domains of everyday life demands a nuanced approach to ethical consumption communication and intervention rather than normalized or universal approaches; and (2) illustrating the common coping strategies - such as neutralization techniques - that are used by consumers as a communication platform, may prove a confronting yet impactful means of shocking or triggering consumers into a moment of 'awakening'. In addition, marketing practitioners can harness 'big data' analysis to identify specific consumption-based issues that are salient in specific contexts and consumer groups - such as environmental degradation - to tailor communication messages to both context and consumer groups as a means of triggering an in-the-moment awakening event.
Marketing managers can anticipate consumers' increasing prominence of their moral lens in the selection of salient role identities and aligned consumption choices. Providing information and offerings that enable the awakened consumer to make domains and fragments of their life, may allow consumers' sense of morality to follow their fluid depict actual versus ideal moral self may form an effective communication platform. 


\section{University Library}

\section{- M M I N E R VA A gateway to Melbourne's research publications}

Minerva Access is the Institutional Repository of The University of Melbourne

Author/s:

Carrington, MJ;Neville, B;Canniford, R

Title:

Unmanageable multiplicity: consumer transformation towards moral self coherence

Date:

2015-01-01

Citation:

Carrington, M. J., Neville, B. \& Canniford, R. (2015). Unmanageable multiplicity: consumer transformation towards moral self coherence. EUROPEAN JOURNAL OF MARKETING, 49 (7-8), pp.1300-1325. https://doi.org/10.1108/EJM-06-2014-0379.

Persistent Link:

http://hdl.handle.net/11343/247860 